\title{
Outcomes and Associated Factors of Mothers Admitted to Intensive Care Unit During Pregnancy and Postpartum at Saint Paul's Hospital Millennium Medical College, Addis Ababa, Ethiopia
}

Tsegaye Mideksa ( $\nabla$ midtsegaye21@gmail.com )

Saint Paul's Hospital Millennium Medical College

Tadios Mekonnen

Saint Paul's Hospital Millennium Medical College

Bezatu Mengiste

Saint Paul's Hospital Millennium Medical College

\section{Research Article}

Keywords: Intensive care unit, Outcome, Pregnancy and Postpartum

Posted Date: February 15th, 2022

DOI: https://doi.org/10.21203/rs.3.rs-1320966/v1

License: (c) (i) This work is licensed under a Creative Commons Attribution 4.0 International License.

Read Full License 


\section{Abstract}

Background: Despite the drastic decrease in maternal morbidity over the last few decades, because of improvements in obstetric care, maternal mortality remains to be a challenge in developing world. Analyzing intensive care unit (ICU) utilization during pregnancy and postpartum is an accepted approach

to identify severe and "near-miss" maternal morbidity. Even though data regarding obstetric admission to ICU is available in developed countries, such data is few or lacking in developing countries specially Ethiopia. The objective of the study was to describe profiles and outcomes of women who required admission to ICU during pregnancy and Postpartum.

Methods: In this cross-sectional study, data from case notes of 154 women who were admitted to the Saint Paul's Hospital Millennium Medical College ICU during pregnancy and postpartum from 2016 to 2020 were collected using simple data extraction format. Mothers admitted over the 5-year period were included in the study. SPSS version 26 was used for data entry and analysis. Data was presented as mean \pm SD and categorical variables as number (percentage). The association between maternal ICU outcome and associated factors was assessed using Binary Logistic regression and P-values less than 0.05 were considered statistically significant.

Results: There were 154 obstetric ICU admissions during the study period. The most common reasons for obstetric ICU admissions were Hypertensive Disorders of Pregnancy (48.7\%) and Obstetric hemorrhage (12.9\%). The mean age of the patients was 27.8 years, and median duration of ICU stay was 5 days (range 1-40 days). Forty-six maternal deaths occurred (29.9\%) and Hypertensive disorders of pregnancy accounted for $45.6 \%$ of all deaths. Not having follow up at this hospital [AOR, 5.480, $\mathrm{Cl}$ (1.890-15.890)] and shorter ICU stay (less than 10 days) [AOR, 0.127, $\mathrm{Cl}(0.028-0.572)]$ were significantly associated with death of mothers admitted to ICU.

Conclusion: Hypertensive disorders of pregnancy were the leading cause of admission to ICU and leading cause of maternal mortality, which can be easily prevented with early diagnosis and timely intervention. Improving the quality of prenatal care to recognize hypertensive disorders during pregnancy, coupled with prompt management, might help to reduce maternal morbidity and mortality.

\section{Introduction}

The intensive care unit (ICU) is an environment where patients with potentially reversible conditions can benefit from more detailed observation and invasive treatment(1). Pregnant and postpartum women are admitted to the ICU at a rate of 0.7 to 13.5 per 1000 deliveries(2-4). Postpartum hemorrhage and hypertensive disorders are the most common reasons for ICU admission(2). In the ICU, however, all medical conditions that can complicate pregnancy are treated.

When critical care is required, maternal mortality is high, with estimates ranging from 3.4 to $14 \%$ in developed countries and 28 percent to $60 \%$ in developing countries $(5,6)$. Cardiovascular illness, venous thromboembolic disease, hemorrhage, infection, and amniotic fluid embolism are all common causes of 
pregnancy-related death. According to one observational study, up to $18 \%$ of maternal deaths could have been avoided (7). Postpartum hemorrhage, hypertension, medication errors, and certain infections were among the preventable causes of mother death.

The ICU care unit has the greatest mortality rate of any unit in any hospital. Understanding the epidemiology of severe obstetric morbidity and "near miss incidents" can aid in the development of interventions aimed at improving the complete spectrum of mother outcomes. The use of intensive care units (ICUs) during pregnancy is a well-accepted method for detecting severe and "near-miss" maternal illness. As a result, there has been a lot of interest in monitoring ICU outcomes and admission characteristics in terms of mortality and resource use $(6,8)$.

In the study area, there is no information concerning ICU patients' profiles and outcomes during pregnancy and postpartum. The objective of this study was to look at the profiles and outcomes of mothers admitted to St. Paul's Hospital Millennium Medical College medical intensive care unit.

\section{Methods}

The present study was a hospital-based retrospective medical record review of the clinical profiles and outcomes of all women admitted to Intensive care unit at SPHMMC, Addis Ababa, Ethiopia, between January 1, 2016, and December 31, 2020. The hospital is located in Addis Ababa, the capital city of Ethiopia, and is a tertiary care teaching hospital that serves a catchment population of more than five million. In 2007 it became a Medical College, its core services including the provision of medical care, teaching and research. Before July 2019 the SPHMMC ICU was a six-bed general intensive care unit which was limited and obviously insufficient to cope with the number of patients being admitted. The new ICU opened in SPHMMC in July 2019 is a locked, 14 bed, self-contained unit including duty rooms for 24 hours physician presence. The unit was designed according to international dimensions.

Source population includes all patients admitted to SPHMMC ICU from January $1^{\text {st }} 2016$ and December $31^{\text {st }}, 2020$, whereas the study population includes all patients admitted to SPHMMC Intensive Care Unit during pregnancy and postpartum from January $1^{\text {st }} 2016$ to December $31^{\text {st }}, 2020$. All women admitted to SPHMMC during pregnancy, at any gestational age, and postpartum were included and those with incomplete medical records were excluded from the study group.

All pregnant and postpartum patients admitted to ICU during the study period that are eligible according to the inclusion criteria were included.

The dependent variable was maternal ICU outcome and the independent variables includes Age, Region, Parity, preexisting condition, time of admission, reason of admission, treatments given and complications encountered at ICU.

Ethical clearance for the study was obtained from the Institutional Review Board of SPHMMC.

Permission was also acquired from the department of Obstetrics and Gynecology , ICU and the hospital 
administration. Informed consent from the patients was not needed because the study was retrospective and secondary data were used. No personal identifiers were used during data collection or reporting.

To retrieve the medical records of all women admitted to ICU during pregnancy and postpartum, the logbook at the Adult ICU was screened for pregnant and postpartum women admitted to ICU during the study period.

All patients who were admitted to the medical ICU of SPHMMC during the study period and whose case notes were available in the hospital registration logbook were included. Case notes were classified according to year of admission. Hence, a total of 168 patients' notes were found during the five-year period in the intensive care unit logbook. However, 154 patient case notes were used for review, the remaining 14 were not included in the analysis due to incomplete data. From the patients' medical records, data related to baseline patient characteristics, comorbidities, reason of admission, outcomes, treatment given and complications encountered at ICU were retrieved using a structured data collection form.

According to criteria of the World Health Organization (WHO), women were defined as "near miss" in cases where they nearly died, but survived a complication that occurred during pregnancy, childbirth or within 42 days postpartum. Regardless of the type of pregnancy, "antepartum" was defined as before the termination of the pregnancy and "postpartum" as after the termination of the pregnancy. "Obstetric reasons" refer to admissions caused by obstetrical complications during pregnancy, labor, or the puerperium, as well as interventions, omissions, incorrect treatment, or a chain of events resulting from any of these factors, whereas "non-Obstetric reasons" refer to previously existing disease or a disease developing during pregnancy, labor, or the puerperium that was aggravated by maternal physiological adaptation to pregnancy.

Data were entered and analyzed using SPSS version 26 (IBM, Armonk, NY, USA). Categorical or nonparametric data were presented as $\mathrm{n}(\%)$ for those not normally distributed and continuous data as mean \pm SD unless otherwise indicated. The association between maternal ICU outcome and associated factors was assessed using Binary logistic regression and those whose P-Value was $<0.25$ were taken to Multivariate Logistic regression and P-values less than 0.05 were considered statistically significant.

\section{Results}

\section{Baseline Patient Characteristics}

Over the 5-year period 154 case notes of patients admitted to ICU during pregnancy and postpartum were reviewed. This contributes for $13 \%$ of all ICU admissions in the study period. The average age of the patients was $27.8 \pm 5.563$ years. Out of the study population $4(2.6 \%)$ were Nulliparous, $75(48.7 \%)$ were primiparous and $75(48.7 \%)$ were multiparous. Post-partum admissions $(n=145,94.2 \%)$ were significantly more as compared to ante-partum admissions $(n=9,5.8 \%)$. 
The highest number of admissions came from the age group of less than or equal to 29 years, $101(65.6 \%)$. The patients were predominantly from Oromia, totaling 86 (55.8\%). (Table 1)

\section{Reasons for Admission}

The various conditions necessitating ICU admissions are shown in Table 2 and 3. Obstetric reasons contribute for most of the ICU admissions, 122(79.2\%). The most common obstetric conditions which necessitated ICU admission included Hypertensive Disorders of Pregnancy $(n=75,47.8 \%)$ and Obstetric Hemorrhage ( $n=20,12.9 \%)$. Others include Infections, Acute fatty Liver of Pregnancy, Respiratory Failure, GTD, one case of IUFD with DIC and one case of Hyperemesis gravidarum complicated with electrolyte abnormalities (Table 2).

The most common non-obstetric admissions are cardiac disorder, 11(7.1\%). Others are Respiratory failure, infections, Anesthesia Complications, Renal disorders, Neurologic disorders and one case of Road Traffic Accident with Acute Subdural Hematoma (Table 2).

The highest number of patients were admitted in the year 2017 (50 patients), whereas the lowest number of patients in the year 2020 (20 patients) (see Figure 1). The pattern of admission of the commonest causes of admission and death at ICU in mothers admitted to Intensive care unit during Pregnancy and Postpartum is shown in Fig 2.

\section{Treatment given at ICU and Complications encountered}

The mean length of stay at the ICU was 7 days (range 1-40) days, A total of 105 (68.2\%) women needed mechanical ventilation. In the majority of patients' antibiotics were given, $149(96.6 \%)$. Almost half of patients received antihypertensive therapy. Inotropic support was given to 63(40.9\%) and blood (and its products) was given to $70(45.5 \%)$ of patients.

Twelve patients underwent at least one session of dialysis. Acute Kidney Injury resulting from Hypertensive disorders of pregnancy is the commonest indication for dialysis ( 9 cases). Other indications include Obstetric hemorrhage (1 case), Infection (1 case) and Other Renal Disorder (1 case). CPR was done for 51 patients and among these only 7 (13.7\%) survived. (Table 4)

A total of 99 patients developed complications at ICU. Among these 51 patients developed only one complication, whereas 48 patients developed two or more complications. Hospital acquired pneumonia is the commonest complication encountered at ICU, 72(46.8\%). Other complications include DIC, 47(30.5\%), Multi organ failure, 39(25.3) and Genitourinary infection, 12(7.8\%) (Table 4).

\section{Outcomes of ICU admission}

A total of $46(29.9 \%)$ women died after ICU admission, whereas 108 (70.1\%) survived. Among the survivors $92(59.7 \%)$ were near miss cases, $2(1.3 \%)$ patients were referred to other hospital and $1(0.6 \%)$ patient left against medical advice (LAMA) (Table 5). 
The top five causes of admissions that accounted for $85 \%$ of total admissions were responsible for $84.7 \%$ of all deaths. Hypertensive disorders of Pregnancy, the commonest cause of admission, are the leading cause of death accounting for $45.6 \%$ of total deaths (Table 6).

Among the top five causes of admission, Infections had the highest case fatality proportion $(71.4 \%)$ followed by obstetric hemorrhage (53.8\%), whereas Anesthesia related complications has not resulted in any death.

Among 105 patients who required mechanical ventilation, 61(58\%) survived, whereas 44(42\%) died. When we compare these based on the length of stay on mechanical ventilation $47.9 \%$ (34/71) of patients who required mechanical ventilation for less than 7 days died while $29 \%(10 / 24)$ of patients who were on mechanical ventilation for more than 7 days died. Most $(96 \%, 47 / 49)$ of those who didn't need mechanical ventilation survived.

Not having follow up at this hospital [AOR, 5.480, $\mathrm{Cl}(1.890-15.890), \mathrm{P}-\mathrm{V}$ alue,0.002] and shorter ICU stay (less than 10 days) [AOR, $0.127, \mathrm{Cl}(0.028-0.572)$, P-value, 0.007$]$ are strongly associated with death of mothers admitted to ICU. Those patients who require mechanical ventilation for less than 7 days are 22.9 times likely to die than those who don't [AOR, 22.932, Cl(4.983-105.540), P-Value <0.001]. Moreover, prolongation of stay on mechanical ventilation for more than 7 days increases the risk of death more [AOR, 37.533, Cl(5.140-274.066), P-Value <0.001] (Table 7).

\section{Discussion}

Despite the fact that pregnancy and birth are physiological processes, any morbidity that occurs during these time periods has the potential to be fatal. As a result, postpartum morbidity has emerged as the most important factor to consider when assessing the quality of maternity care. As a result, the importance of continuing to seek to implement methods for the early detection and management of morbidity in maternity care is emphasized. Despite recent improvements in the standard of care in ICUs, maternal mortality continues to be a problem.(6).

Hypertensive disorders of pregnancy and obstetric hemorrhage were the most common reasons for MICU admission throughout pregnancy and postpartum in the current study, and they were also associated with the greatest fatality rates. Pre-eclampsia or eclampsia, as well as obstetric hemorrhage, were the most common reasons for ICU admission in previous studies. $(5,9-12)$ Our findings confirmed that these are the most common indications. There is also evidence that mothers in intensive care units have a higher prevalence of obstetric hemorrhage, cardiac disorders, and infections. Infection is one of the most prevalent reasons for ICU hospitalization, accounting for 8 to 30 percent of all admissions $(9,12,13)$. In our study, infectious reasons accounted for just $7.8 \%$ of obstetric ICU admissions. The majority of these patients most likely died before admission to the Obstetric ICU (13). The higher rate of obstetric compared to medical complications is consistent with findings of other studies from developing countries. 
The average length of ICU stay was 7 days, which is comparable with study by Togal et al in Turkey and longer than study done in Vienna by Alexx Farr, et al (6). The longer duration of the ICU stay would reflect the severity of the patient's clinical condition, hence necessitating early and elective admission to the ICU for patients at high risk. The percentage of the patients requiring intubation and mechanical ventilation in the present study was relatively high (68.2\%). In comparison, the percentage of the obstetric patients requiring mechanical ventilation in the ICU has been reported as $19 \%$ by Selo-Ojeme et al (14), $41 \%$ by Cohen et al (15), and $64 \%$ by Tripathi et al (16). Late referrals with complicated stage of the diseases may contribute for the higher need of mechanical ventilation in this study.

The overall MICU mortality rate during pregnancy and postpartum was $29.9 \%$, according to this study. This study's mortality rate is higher than that of developed countries, which is $5 \%$ in a study by Alex Farr, et al. at the Medical University of Vienna, Vienna General Hospital, and is slightly lower than that of T S Ntuli, et al. at a tertiary hospital in Lipo Province, South Africa, which is 34.8 percent (17). Lack of proper antenatal care, late referrals, poor transportation facilities, limited specialist obstetrician and critical care specialist support, long distances to the referral hospital, and inadequate emergency obstetric care at centers close to patient residences are all possible reasons for the high maternal mortality rate in our study.

Survivors stayed in the ICU for a statistically significant longer time than non-survivors, which is consistent with other research in underdeveloped countries (8), but contrary to studies in developed countries which reported non-survivors staying longer than survivors $(18,19)$. This disparity in survival is likely due to a combination of factors, including the severity of the patient's health condition, poor prehospital care, a lack of emergency medical services, and a lack of appropriate diagnostic and therapeutic facilities, including drugs, for the hospital and ICU care of these patients. Failure to follow up at this referral center and the necessity for mechanical ventilation were also linked to an increased risk of death, a conclusion that was consistent with previous research. This is due to the fact that these individuals are frequently referred late.

The study's strength is that it included a reasonably large number of participants when compared to similar studies done in other areas. The study sample consisted of varied cases and at various stages of presentation. The study evaluated maternal outcome as a continuum, ranging from severe morbidity, near miss events and to maternal death. Limitations of this study include its retrospective nature with the consequence that it could not provide the same level of evidence as a prospective survey. Particularly, due to the concise format of medical records, only limited data could be retrieved for this audit. Furthermore, the duration of this study was only 5 years. A longer duration could have resulted in either a higher or lower maternal mortality rate from the obstetric ICU admissions at this hospital. Inability to include all case notes due to loss of the documents and incomplete data are the other limitations.

\section{Conclusion}


In conclusion, hypertensive disorders of pregnancy and Obstetric hemorrhage were the primary reasons of admission to ICU for pregnant and postpartum mothers, both of which can be readily avoided with early diagnosis and quick care. In this study, these diseases were also the primary causes of maternal death after ICU admission. The majority of the women in this study had no follow up at this hospital and were referred after they developed a condition that led to ICU admission, showing that these illnesses are not adequately diagnosed early enough for treatments. Improving the quality of prenatal care to diagnose these illnesses and begin treatment as soon as possible might prevent many cases of maternal morbidity and mortality.

\section{Abbreviations}

AFLP - Acute Fatty Liver of Pregnancy, AOR - Adjusted Odds Ratio, $\mathrm{Cl}$ - Confidence Interval, COR Crudes Odds Ratio, CPR - Cardiopulmonary Resuscitation, DIC - Disseminated Intravascular Coagulation, GTD - Gestational Trophoblastic Disease, HAP - Hospital acquired pneumonia, HDP Hypertensive Disorders of Pregnancy, ICU - Intensive Care Unit, IRB - Institutional Review board, IUFD Intrauterine Fetal Death, LAMA - Left against medical advice, MICU - Medical Intensive Care Unit, OBGYN - Obstetrics and Gynecology, SD - Standard Deviation, SNNPR - South Nations Nationalities and People, SPHMMC - Saint Paul's Hospital Millennium Medical College, SPSS - Statistical Package for the Social Sciences, WHO - World Health Organization

\section{Declarations}

\section{Ethics approval and consent to participate}

The study was conducted in accordance to the declaration of Helsinki. The protocol was approved by the IRB of SPHMMC, date 24/2/2020. Informed consent was waived as it was a retrospective chart review study.

\section{Consent for publication}

All authors agreed for publication of this article.

\section{Availability of data and materials}

The datasets used and/or analyzed during the current study available from the corresponding author on reasonable request.

\section{Competing interests}

The authors declared no potential conflicts of interest with respect to the research, authorship, and/or publication of this article.

\section{Funding}


This research did not receive any specific grant from funding agencies in the public, commercial, or not for- profit sectors.

\section{Authors' contributions}

TsM: Conceptualization, Methodology, Analysis, Writing- Original draft preparation. TM: Analysis, Discussion, Editing BM: Supervision, Writing- Reviewing and Editing.

All authors read and approved the final manuscript.

\section{Acknowledgements}

Not applicable.

\section{References}

1. Nielsen GSaM. ABC of Intensive care. British Medical Journal. 1999;318(7197). https://doi: 10.1136/ bmj.318.7197.1544.

2. Pollock W, Rose L, Dennis C-L. Pregnant and postpartum admissions to the intensive care unit: a systematic review. Intensive care medicine. 2010;36(9):1465-74. https://pubmed.ncbi.nlm.nih.gov/20631987/

3. Chantry AA D-TC, Bonnet MP. Pregnancy-related ICU admissions in France: trends in rate and severity, 2006-2009. Crit Care Med. 2015;43(78). https://doi: 10.1097/CCM.0000000000000601

4. Guntupalli KK, Hall N, Karnad DR, Bandi V, Belfort M. Critical illness in pregnancy: part I: an approach to a pregnant patient in the ICU and common obstetric disorders. Chest. 2015;148(4):1093-104.

5. Vasquez DN, Estenssoro E, Canales HS, Reina R, Saenz MG, Neves AVD, et al. Clinical characteristics and outcomes of obstetric patients requiring ICU admission. Chest. 2007;131(3):718-24. https://doi: 10.1378/ chest.06-2388.

6. Turkan Togal EG, Neslihan Yusel. Obstetric admission to the intensive care unit in a tertiary referral Hospital. Journal of Critical care. 2010;25:625 - 33. https"//Doi: 10.1016/j.jcrc.2010.02.015. Epub 2010 Apr 8.

7. Clark SL BM, Dildy GA. Maternal death in the 21st century: Causes, Preventionand relationship to cesarean delivery. Am J Obstet Gynecol. 2008;199(36 e1). https://Doi:

10.1016/j.ajog.2008.03.007. Epub 2008 May 2.

8. Bayisa T, Berhane A, Kedir S, Wuletaw T. ADMISSION PATTERNS AND OUTCOMES IN THE MEDICAL INTENSIVE CARE UNIT OF ST. PAUL'S HOSPITAL MILLENNIUM MEDICAL COLLEGE, ADDIS ABABA, ETHIOPIA. Ethiopian medical journal. 2017;55(1).

9. Richa F KN, Yazbeck P. Obstetric admissions to the intensive care unit: An eight year review. J Med Liban. 2008; 56(4). https://dx.doi.org/10.18203/2320-1770.ijrcog20182905 
10. Keizer JL, Zwart JJ, Meerman RH, Harinck BI, Feuth HD, van Roosmalen J. Obstetric intensive care admissions: a 12-year review in a tertiary care centre. European Journal of Obstetrics \& Gynecology and Reproductive Biology. 2006;128(1-2):152-6. http://dx.doi.org/10.1007/s00134-009-1707-x

11. Crozier TM WE. Obstetric admissions to an integrated general intensive care unit in a quaternary maternity facility. . Aust N Z J Obstet Gynaecol 2011;51(3). https://doi: 10.1111/j.1479828X.2011.01303.x. Epub 2011 Mar 16.

12. Leung NY LA, Chan KK, Yan WW. Clinical characteristics and outcomes of obstetric patients admitted to the intensive care unit: A 10-year retrospective review. Hong Kong Med J. 2010;16(1).

13. Ntuli TS, Ogunbanjo G, Nesengani S, Maboya E, Gibango M. Obstetric intensive care admissions at a tertiary hospital in Limpopo Province, South Africa. Southern African Journal of Critical Care (Online). 2015;31(1):8-10. https://dx.doi.org/10/7196/SAJCC.164

14. Selo-Ojeme DO OM, Battacharjee $P$, et al. Risk factors for obstetric admissions to the intensive care unit in a tertiary hospital: a case-control study. . Arch Gynecol Obstet 2005;. 2005;272. https://doi: 10.1007/s00404-004-0695-x. Epub 2005 Feb 3.

15. Cohen J SP, Kogan A, et al. Course and outcome of obstetric patients in a general intensive care unit. Acta Obstet Gynecol Scand. 2000;79.

16. Tripathi R RA, Saran S. . Intensive care for critically ill obstetric patients. . Int J Gynaecol Obstet. 2000;68. https://doi: 10.1016/s0020-7292(99)00200-3.

17. Farr A, Lenz-Gebhart A, Einig S, Ortner C, Holzer I, Elhenicky M, et al. Outcomes and trends of peripartum maternal admission to the intensive care unit. Wiener Klinische Wochenschrift. 2017;129(17-18):605-11. scielo.sld.cu/pdf/mmed/v23n2/1028-4818-mmed-23-02-280.pdf

18. Guidelines for intensive care unit admission, discharge, and triage. Task Force of the American College of Critical Care Medicine, Society of Critical Care Medicine. . . Crit Care Med. 1999;27. https://pubmed.ncbi.nlm.nih.gov/10199547/

19. Yaseen A VS, Samir H, Abdillah S, Salim M. . A prospective study of prolonged stay in the intensive care unit: Predictors and impact on resource utilization. International Journal for Quality in Health Care. 2002;14(5). https://doi: 10.1093/intqhc/14.5.403

\section{Tables}

Table 1. Baseline characteristics of patients admitted to Medical Intensive Care Unit during pregnancy and postpartum, St. Paul's Hospital Millennium Medical College, 2016-2020 
Characteristic features

Frequency Percent

\begin{tabular}{llll}
\hline Age in years & $<20$ & 11 & 7.1 \\
\hline $20-24$ & 30 & 19.5 \\
\hline $25-29$ & 60 & 39 \\
\hline $30-34$ & 29 & 18.8 \\
\hline $35-39$ & 19 & 12.3 \\
\hline$\geq 40$ & 5 & 3.2 \\
\hline Region & Addis Ababa & 41 & 26.6 \\
\cline { 2 - 4 } & Oromia & 86 & 55.8 \\
\cline { 2 - 4 } & SNNPR & 17 & 11 \\
\cline { 2 - 4 } & Amhara & 10 & 6.5 \\
\hline Parity & Nulliparous/Primiparous & 79 & 51.3 \\
\cline { 2 - 4 } Time of admission & Multiparous & 75 & 48.7 \\
\hline Had follow up at SPHMMC & Antepartum & 9 & 5.8 \\
\cline { 2 - 4 } & Postpartum & 145 & 94.2 \\
\cline { 2 - 4 } & No & 50 & 32.5 \\
\hline
\end{tabular}

Table 2. Reasons of admission to Medical Intensive Care Unit during pregnancy and postpartum, St. Paul's Hospital Millennium Medical College, 2016-2020 


\begin{tabular}{lll} 
Obstetric Reasons of admission & Frequency & Percent \\
\hline Hypertensive Disorders of Pregnancy & 75 & 48.7 \\
\hline Obstetric Hemorrhage & 20 & 13.0 \\
\hline Infection & 7 & 4.5 \\
\hline Peripartum cardiomyopathy & 2 & 1.3 \\
\hline AFLP & 5 & 3.2 \\
\hline IUFD with DIC & 1 & 0.6 \\
\hline Hyperemesis Gravidarum & 1 & 0.6 \\
\hline Respiratory Failure & 6 & 3.9 \\
\hline GTD & 5 & 3.2
\end{tabular}

\section{Non-Obstetric reasons of admission}

\begin{tabular}{lll} 
Cardiac Disorders & 11 & 7.1 \\
\hline Respiratory Failure & 5 & 3.2 \\
\hline Infection & 5 & 3.2 \\
\hline Renal Disorder & 4 & 2.6 \\
\hline Neurologic Disorder & 2 & 1.3 \\
\hline Anesthesia Complications & 4 & 2.6 \\
\hline Trauma & 1 & 0.6
\end{tabular}

Table 3. Treatments given for mothers admitted to Medical Intensive Care Unit during pregnancy and postpartum, St. Paul's Hospital Millennium Medical College, 2016-2020 


\begin{tabular}{lll} 
Treatment given & Frequency & Percent \\
\hline Antibiotics & 149 & 96.6 \\
\hline Blood and blood products & 70 & 45.5 \\
\hline Antihypertensives & 75 & 48.7 \\
\hline Anticoagulants & 83 & 53.9 \\
\hline Catecholamines & 63 & 40.9 \\
\hline CPR & 51 & 33.1 \\
\hline Dialysis & 12 & 7.8
\end{tabular}

Table 4. Complications encountered at Medical Intensive Care Unit during pregnancy and postpartum, St. Paul's Hospital Millennium Medical College, 2016-2020

\begin{tabular}{lll} 
Complications Encountered & Frequency & Percent \\
\hline DIC & 47 & 30.5 \\
\hline Multi organ failure & 39 & 25.3 \\
\hline HAP & 72 & 46.8 \\
\hline Genitourinary Infection & 12 & 7.8
\end{tabular}

Table 5. Outcomes of admissions to Medical Intensive Care Unit during pregnancy and postpartum, St. Paul's Hospital Millennium Medical College, 2016-2020

\begin{tabular}{llll}
\multicolumn{2}{l}{ Outcomes of ICU Admission } & Frequency & Percent \\
\hline Survivors & Recovered & 13 & 8.4 \\
\cline { 2 - 4 } & Near miss & 92 & 59.7 \\
\cline { 2 - 4 } & Referred & 2 & 1.3 \\
\cline { 2 - 4 } & LAMA & 1 & 0.6 \\
\hline Non-survivors & 46 & 29.9
\end{tabular}

Table 6. Outcomes of Top 7 causes of admissions to Medical Intensive Care Unit during pregnancy and postpartum, St. Paul's Hospital Millennium Medical College, 2016-2020 


\begin{tabular}{lllll} 
Diseases & Survivors & $\begin{array}{l}\text { Non- } \\
\text { survivors }\end{array}$ & $\begin{array}{l}\text { Specific cause of death (as \% of } \\
\text { total death) }\end{array}$ & $\begin{array}{l}\text { Case Fatality } \\
\text { Rate\%) }\end{array}$ \\
\hline HDP & 54 & 21 & 45.6 & 38.9 \\
\hline $\begin{array}{l}\text { Obstetric } \\
\text { Hemorrhage }\end{array}$ & 13 & 7 & 15.2 & 53.8 \\
\hline $\begin{array}{l}\text { Cardiac } \\
\text { Disorders }\end{array}$ & 10 & 3 & 6.5 & 30 \\
\hline $\begin{array}{l}\text { Infection } \\
\begin{array}{l}\text { Respiratory } \\
\text { Failure }\end{array}\end{array}$ & 7 & 5 & 10.9 & 71.4 \\
\hline
\end{tabular}

Table 7. Factors associated with outcomes admission to Medical Intensive Care Unit during pregnancy and postpartum, St. Paul's Hospital Millennium Medical College, 2016-2020 
Factor

ICU Outcome

$\operatorname{COR}(95 \% \mathrm{Cl})$

AOR $(95 \% \mathrm{Cl})$

P-

Survivors Non-

Value survivors

\begin{tabular}{|c|c|c|c|c|c|c|}
\hline \multirow[t]{3}{*}{ Age } & $20-34$ & 89 & 31 & 1 & & \\
\hline & $<20$ & 5 & 5 & $\begin{array}{l}2.871(0.778 \\
-10.590)\end{array}$ & $\begin{array}{l}5.581(0.915- \\
34.049)\end{array}$ & 0.062 \\
\hline & $\geq 35$ & 14 & 10 & $\begin{array}{l}2.051(0.827 \\
-5.088)\end{array}$ & $\begin{array}{l}1.064(0.341- \\
3.319)\end{array}$ & 0.915 \\
\hline \multirow[t]{2}{*}{ Parity } & Multipara & 55 & 20 & 1 & & \\
\hline & Primipara & 53 & 26 & $\begin{array}{l}1.349(0.674- \\
2.701)\end{array}$ & $\begin{array}{l}1.763(0.649- \\
4.789)\end{array}$ & 0.266 \\
\hline \multirow{2}{*}{$\begin{array}{l}\text { Follow up at } \\
\text { SPHMMC }\end{array}$} & Yes & 44 & 6 & 1 & & \\
\hline & No & 64 & 40 & $\begin{array}{l}0.218(0.085 \\
-0.599)\end{array}$ & $\begin{array}{l}5.480(1.890- \\
15.890)\end{array}$ & 0.002 \\
\hline \multirow[t]{2}{*}{ Region } & $\begin{array}{l}\text { Addis } \\
\text { Ababa }\end{array}$ & 26 & 15 & 1 & & \\
\hline & Others & 82 & 31 & $\begin{array}{l}0.655(0.307- \\
1.398)\end{array}$ & $\begin{array}{l}0.431(0.160- \\
1.160)\end{array}$ & 0.096 \\
\hline \multirow{7}{*}{$\begin{array}{l}\text { Reason of } \\
\text { Admission }\end{array}$} & Hemorrhage & 13 & 7 & 1 & & \\
\hline & HDP & 54 & 21 & $\begin{array}{l}0.923(0.249- \\
3.417)\end{array}$ & $\begin{array}{l}1.225(0.371- \\
4.740)\end{array}$ & 0.769 \\
\hline & $\begin{array}{l}\text { Cardiac } \\
\text { disorders }\end{array}$ & 10 & 3 & $\begin{array}{l}0.667(0.231- \\
1.924)\end{array}$ & $\begin{array}{l}1.507(0.174- \\
13.019)\end{array}$ & 0.709 \\
\hline & Infection & 7 & 5 & $\begin{array}{l}0.514(0.105- \\
2.526)\end{array}$ & $\begin{array}{l}1.676(0.253- \\
11.120)\end{array}$ & 0.593 \\
\hline & $\begin{array}{l}\text { Respiratory } \\
\text { Failure }\end{array}$ & 8 & 3 & $\begin{array}{l}1.224(0.279- \\
5.371)\end{array}$ & $\begin{array}{l}1.637(0.223- \\
12.027\end{array}$ & 0.628 \\
\hline & $\begin{array}{l}\text { Anesthesia } \\
\text { related }\end{array}$ & 4 & 0 & & & 0.999 \\
\hline & Others & 12 & 7 & $\begin{array}{l}0.643(0.127- \\
3.254)\end{array}$ & $\begin{array}{l}3.153(0.545- \\
18.234)\end{array}$ & 0.200 \\
\hline \multirow{3}{*}{$\begin{array}{l}\text { Ventilation } \\
\text { Requirement in } \\
\text { days }\end{array}$} & None & 47 & 2 & 1 & & \\
\hline & $<7$ & 37 & 34 & $\begin{array}{l}21.595(4.868 \\
-95.791)\end{array}$ & $\begin{array}{l}22.932(4.983- \\
105.540)\end{array}$ & $0.000^{\circ}$ \\
\hline & $\geq 7$ & 24 & 10 & $\begin{array}{l}9.792(1.985- \\
48.297)\end{array}$ & $\begin{array}{l}37.533(5.140- \\
274.066)\end{array}$ & $0.000^{\circ}$ \\
\hline
\end{tabular}

ICU Stay in days

29

6

1




\section{Figures}

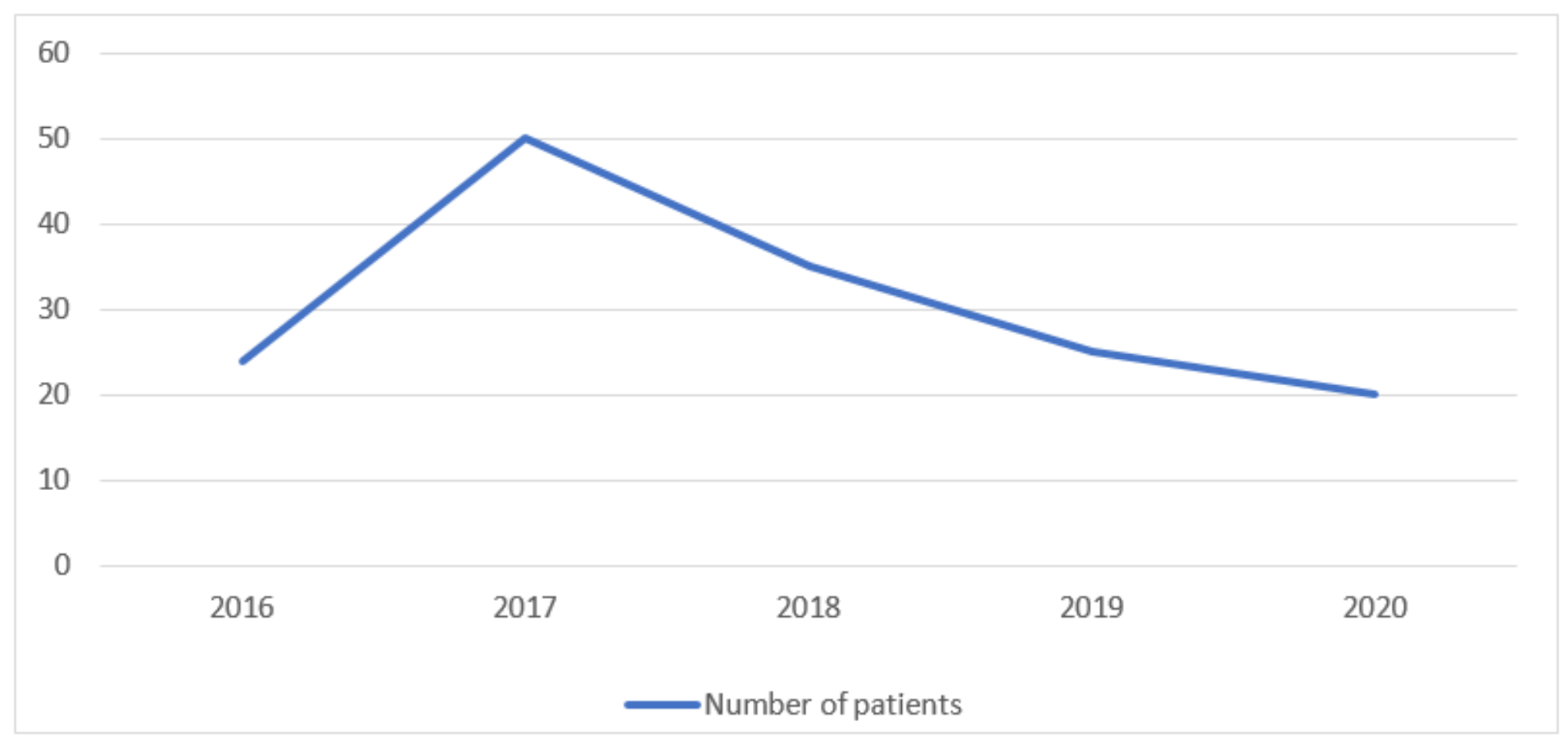

\section{Figure 1}

Trends of patient admission to Medical Intensive Care Unit during pregnancy and postpartum, St. Paul's Hospital Millennium Medical College, 2016-2020 
30

25

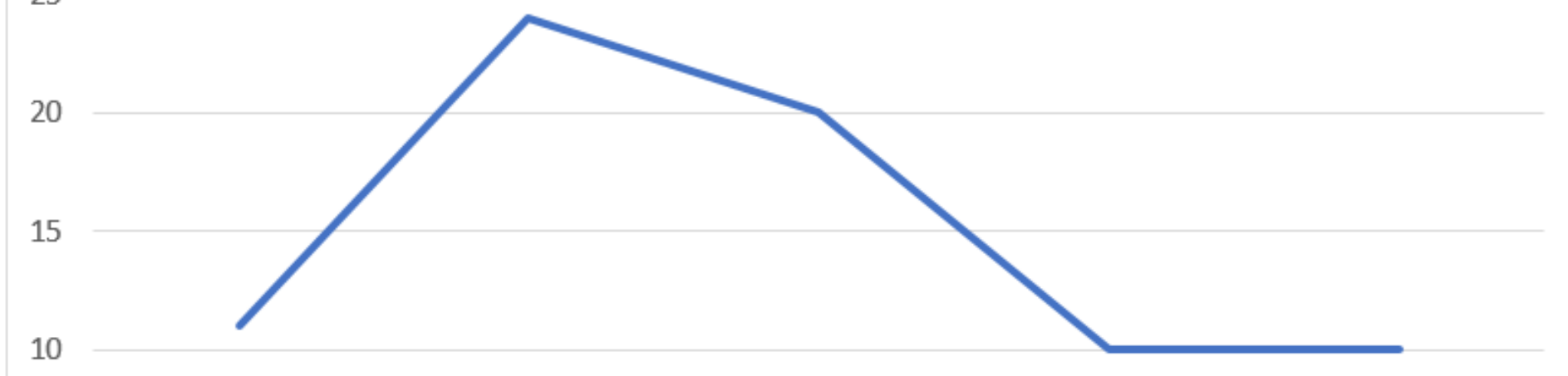

5

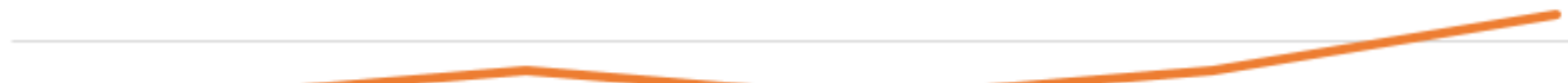

0
2016
2017
2018
2019
Hypertensive Disorders of Pregnancy —obstetric Hemorrhage

2020

\section{Figure 2}

Trends of Admissions on the most common Diseases to Medical Intensive Care Unit during pregnancy and postpartum, St. Paul's Hospital Millennium Medical College, 2016-2020 